\title{
PENGARUH STRESOR PSIKOLOGIS DAN STRESOR SOSIAL TERHADAP SIKLUS MENSTRUASI
}

\author{
Romauli $^{1}$, Regina Marintan ${ }^{2}$, Nurul Utami $^{3}$ \\ ${ }^{1,2}$ Staff Pengajar Akademi Kebidanan Dewi Maya, Medan Selayang, 20131, Indonesia \\ ${ }^{3}$ Staf Pengajar Universitas Islam Sumatera Utara, Medan Kota, 20143, Indonesia
}

\author{
Informasi Artikel: \\ Diterima: Agustus, 2016 \\ Disetujui: September, 2017 \\ ${ }^{*}$ Korespondensi penulis. \\ Nainggolan.aries@yahoo.co.id
}

\begin{abstract}
ABSTRAK
Stres dapat memengaruhi siklus menstruasi karena hormon stres yaitu hormon kortisol mempengaruhi jumlah hormon progesteron dalam tubuh. Mahasiswi kebidanan mengalami menstruasi tidak teratur pada saat menjelang ujian, ada konflik hubungan interpersonal dengan teman, dan tugas kuliah sedang menumpuk. Penelitian ini bertujuan untuk mengetahui pengaruh stressor psikologis dan stresor sosial terhadap siklus menstruasi mahasiswa kebidanan Dewi Maya Medan. Penelitian ini dilaksanakan pada bulan FebruariMaret 2016. Penelitian ini adalah penelitian survei analitik dengan desain cross sectional. Jumlah sampel adalah 68 orang. Pengambilan data menggunakan lembar checklist mengukur tingkat stess melalui Depression Anxiety Stress Scale (DASS) yang telah dimodifikasi DASS dalam bentuk skala linkert. Data dianalisis dengan menggunakan uji chi-square. Hasil penelitian menunjukkan bahwa menunjukkan terdapat pengaruh stressor psikologis terhadap siklus menstruasi mahasiswa kebidanan $(\mathrm{p}=0,014)$ dan terdapat pengaruh stressor sosial terhadap siklus menstruasi $(p=0,049)$.
\end{abstract}

kata kunci: Menstruasi, Stress, Psikolgis, Sosial, Mahasiswa

\begin{abstract}
Stress can affect the menstrual cycle because the hormone of stress cortisol hormone which affects the amount of progesterone in the body. The college student of midwifery experience irregular periods at the time before the exam, there is a conflict of interpersonal relationships with friends, and the coursework is accumulate. This study aimed to determine influence of psychological stressors and social stressors of the menstrual cycle midwifery students Dewi Maya Medan from february to march 2016. This was an analytical survey with a cross sectional study design. The sample size was 68 people. Data collection used checklist sheet which contained stress level gauge through the Depression Anxiety Stress Scale (DASS) that have been modified DASS in the form of Linkert scale. We used chisquare test to analysis data. The result shows there was a influence of psychological stressor and menstrual cycle $(p=0,014)$ and there was $(p=0.049)$.
\end{abstract}

Keyword: Menstrual, Stress, Psychological, Social, Student

\section{PENDAHULUAN}

Gangguan pola menstruasi yang berhubungan pada siklus menstruasi terdiri dari tiga, yaitu siklus menstruasi pendek yang disebut dengan Polimenore, siklus menstruasi panjang atau oligomenore, dan amenore jika menstruasi tidak datang dalam 3 bulan berturut-turut. Gangguan pola menstruasi berdasarkan lama perdarahan menstruasinya dapat digolongkan menjadi 2 yaitu perdarahan haid yang lebih pendek dan atau kurang dari biasa yang disebut hipomenorea dan perdarahan haid yang lebih banyak dari normal yang disebut hipermenorea. (Wiknjosastro, 2009).
Cakir M. et all (2009), dalam penelitiannya menemukan bahwa nyeri menstruasi merupakan gangguan pola menstruasi dengan prevalensi terbesar $(89,5 \%)$, diikuti ketidakteraraturan menstruasi $(31,2 \%)$, serta perpanjangan durasi menstruasi $(5,3 \%)$ dengan prevalensi tertinggi ada pada remaja. Nyeri menstruasi merupakan alasan utama yang menyebabkan remaja putri absen dari sekolah. Efek gangguan menstruasi yang dilaporkan antara lain waktu istirahat yang memanjang (54\%) dan menurunnya kemampuan belajar $(50 \%)$.

Siklus tidak teratur terjadi dimasa remaja hingga dewasa. Kondisi ini disebut sebagai wanita 
mengalami Polycystic Ovarium Syndrome (PCOS). Gejala ini diketahui banyak remaja wanita, dengan mulai mengenal masa stres sampai bisa mengalami sindrom. Karena, PCOS dapat dideteksi sejak masa usia dini dan remaja. Dikutip Times of India, PCOS merupakan kelainan endokrin yang ditandai dengan meningkatnya hormon pria (androgen) di dalam tubuh. Ini akan mengganggu pertumbuhan dan pelepasan sel telur dari ovarium. Akibatnya ovulasi tidak terjadi dan menstruasi menjadi kurang teratur.Bagi wanita yang mengalami masalah PCOS dapat beresiko tinggi terhadap hipertensi, koleterol tinggi, hingga kanker endometrium. Sehingga, mereka lebih cenderung resisten pada insulin sehingga rentan terkena diabetes. tanda yang bisa dilihat misalnya penambahan berat badan, pertumbuhan rambut di tubuh dan wajah, penipisan rambut kepala, berjerawat dan kemandulan.

Berdasarkan informasi bahwa banyak mahasiswa yang mengalami siklus menstruasi yang tidak teratur. Penelitian ini penting untuk dilakukan agar dapat mengetahui siklus menstruasi serta keterkaitannya atau pengaruhnya dengan stressor psikologis dan stresor sosial.

\section{BAHAN DAN METODE}

Jenis penelitian yang digunakan dalam penelitian ini adalah penelitian survei analitik dengan desain penelitian Cross Sectional. Survei Analitik adalah survei atau penelitian yangmencoba menggali bagaimana dan mengapa fenomena kesehatan itu terjadi. Kemudian, analisis dinamika korelasi antara fenomena atau antara faktor resiko dan faktor efek dilakukan.

Penelitian ini dilaksanakan di salah satu Akademi Kebidanan di Medan. Pengambilan data dilakukan pada bulan Februari - Maret 2016. Populasi dalam penelitian ini adalah semua mahasiswa tingkat I dan II Akademi Kebidanan Dewi Maya Medan yang berjumlah 68 orang. Sampel dalam penelitian in adalah seluruh populasi dijadikan sampel (Total Population) sebanyak 68 orang

Peneliti menggunakan instrumen penelitian kuesioner dengan mengukur tingkat stess melalui Depression Anxiety Stress Scale (DASS) yang telah dimodifikasi DASS merupakan instrumen yang digunakan oleh Lovibon (1995) dalam bentuk skala likert yang dibagikan kepada responden.
Analisis univariat dapat menggambarkan tentang distribusi frekuensi responden dari sampel yang diteliti, seperti stressor psikologis stresor sosial, dan siklus menstruasi. Analisis bivariat adalah tahapan untuk mengetahui apakah terdapat pengaruh stresor psikologis stresor sosial terhadap siklus menstruasi dengan menggunakan Chi Square Test. Program analisis menggunakan perangkat lunak dengan tingkat kesalahan $\alpha=$ 0,05 . Penelitian ini senantiasa menjunjung tinggi kaidah-kaidah penelitian, yaitu informed Consent, anonimity, danconfidentiality.

\section{HASIL DAN PEMBAHASAN}

Hasil - hasil penelitian dapat dilihat pada tabeltabel yang disajikan. Tabel 1 memperlihatkan hasil distribusi usia responden berdasarkan usia

Tabel 1. Karakteristik Responden berdasarkan usia

\begin{tabular}{lcc}
\hline Usia & n & \% \\
\hline 18 tahun & 19 & 27,9 \\
19 tahun & 45 & 66,2 \\
20 tahun & 4 & 5,9 \\
Total & $\mathbf{6 8}$ & $\mathbf{1 0 0 . 0}$ \\
\hline
\end{tabular}

Sumber : Data Primer 2016

Berdasarkan tabel di atas, 45 orang $(66,2 \%)$ adalah usia 19 tahun, 19 orang $(27,9 \%)$ adalah usia 18 tahun dan 4 orang (5,9\%) adalah usia 20 tahun. Dimana untuk usia yang lebih muda itu adalah mahasiswi semester I dan yang lebih tua merupakan mahasiswi semester III.

Tabel 2: Distribusi Stresor Psikologis pada responden

\begin{tabular}{lcc}
\hline Stresor Psikologis & n & \% \\
\hline Berat & 38 & 55,9 \\
Ringan & 30 & 44,1 \\
Total & $\mathbf{6 8}$ & $\mathbf{1 0 0 . 0}$ \\
\hline
\end{tabular}

Sumber : Data Primer 2016

Berdasarkan tabel di atas, 38 orang $(55,9 \%)$ adalah stresor psikologis berat dan 30 orang $(44,1 \%)$ adalah stresor psikologis ringan. Dimana untuk mahasiswi semester I secara keseluruhan mengalami stresor psikologis berat.

Tabel 3: Distribusi Stresor Sosial Pada Responden

\begin{tabular}{lcc}
\hline Stresor Sosial & n & \% \\
\hline Tidak baik & 21 & 30,9 \\
Baik & 47 & 69,1 \\
Total & $\mathbf{6 8}$ & $\mathbf{1 0 0 . 0}$ \\
\hline Sumber : Data Primer 2016 & &
\end{tabular}


Berdasarkan tabel di atas, 21 orang (30,9\%) adalah stresor sosial tidak baik dan 47 orang $(69,1 \%)$ adalah stresor sosial baik.

Tabel 4: Distribusi Siklus Menstruasi pada responden

\begin{tabular}{lcc}
\hline Siklus & n & \% \\
Menstruasi & 27 & 39,7 \\
\hline Tidak normal & 41 & 60,3 \\
Normal & $\mathbf{6 8}$ & $\mathbf{1 0 0 . 0}$ \\
Total & & \\
\hline
\end{tabular}

Berdasarkan tabel di atas, 27 orang $(39,7 \%)$ adalah siklus menstruasi tidak normal dan 41 orang $(60,3 \%)$ adalah siklus menstruasi normal.

Hasil penelitian yang menghubungkan stresor psikologis dan stressor sosial dengan siklus menstruasi dapat dilihat pada Tabel 5 dan tabel 6 .

Tabel 5: Pengaruh Stresor Psikologis Terhadap Siklus Menstruasi Pada Mahasiswa

\begin{tabular}{|c|c|c|c|c|}
\hline \multirow{2}{*}{$\begin{array}{l}\text { Stresor } \\
\text { Psikologis }\end{array}$} & \multicolumn{2}{|c|}{ Siklus Menstruasi } & \multirow[b]{2}{*}{ Total } & \multirow{2}{*}{$\begin{array}{c}\text { Nilai } \\
\mathbf{p}\end{array}$} \\
\hline & $\begin{array}{c}\text { Tidak } \\
\text { Normal }\end{array}$ & Normal & & \\
\hline Berat & 20 & 18 & 38 & \\
\hline Ringan & 7 & 23 & 30 & 0,014 \\
\hline Total & 27 & 41 & 68 & \\
\hline
\end{tabular}

Tabel 6: Analisis Pengaruh Stresor Sosial Terhadap Siklus Menstruasi Pada Mahasiswa

\begin{tabular}{ccccc}
\hline $\begin{array}{c}\text { Stresor } \\
\text { Sosial }\end{array}$ & \multicolumn{2}{c}{ Siklus Menstruasi } & & Nilai \\
& $\begin{array}{c}\text { Tidak } \\
\text { Normal }\end{array}$ & Normal & Total & $\mathbf{p}$ \\
\hline Tidak baik & 12 & 9 & 21 & \\
Baik & 15 & 32 & 47 & 0,049 \\
$\quad$ Total & $\mathbf{2 7}$ & $\mathbf{4 1}$ & $\mathbf{6 8}$ & \\
\hline
\end{tabular}

\section{a. Stresor Psikologis}

Stressor adalah faktor-faktor dalam kehidupan manusia yang mengakibatkan terjadinya respon stres. Stressor dapat berasal dari berbagai sumber, baik dari kondisi fisik, psikologis, maupun sosial dan juga muncul pada situasi kerja, dirumah, dalam kehidupan sosial, dan lingkungan luar lainnya. Istilah stressor diperkenalkan pertama kali oleh Selye (Rice, 2002). Responden dengan stresor psikologis berat yang siklus menstruasi tidak normal adalah sebanyak 20 orang $(52,6 \%)$, dan yang siklus menstruasi normal adalah sebanyak 18 orang $(47,4 \%)$. Sementara itu, responden dengan stresor psikologis ringan yang siklus menstruasi tidak normal adalah sebanyak 7 orang $(23,2 \%)$, dan yang siklus menstruasi normal adalah sebanyak 23 orang $(76,8 \%)$.

Menurut Wulandari (2011), menyatakan bahwa stres akademik merupakan stres yang disebabkan oleh stressor akademik, yaitu yang bersumber dari proses belajar mengajar atau yang berhubungan dengan kegiatan belajar yang meliputi lama belajar, banyaknya tugas, keputusan menentukan jurusan, dan kecemasan ujian. Cemas adalah suatu keadaan perasaan dimana individu merasa lemah sehingga tidak berani untuk bersikap dan bertindak secara rasional sesuai dengan yang seharusnya. Seseorang yang cemas akan merasa ketakutan atau kehilangan kepercayaan diri yang tidak jelas asal maupun wujudnya (Wiramihardja, 2007).

Penelitian yang dilakukan oleh Sukhraini (2010) tentang hubungan stress dengan siklus menstruasi yang tidak teratur di Medan pada tahun 2010. Penelitian ini juga menunjukkan bahwa dari 110 orang sampel yang mengalami stres, didapatkan 33 orang (30\%) mengalami siklus menstruasi yang tidak teratur.

Kondisi stres juga mendorong terjadinya perubahan perilaku pada mahasiswa seperti penurunan minat dan efektivitas, penurunan, energi, cenderung mengekspresikan pandangan sinis pada orang lain, perasaan marah, kecewa, frustasi, bingung, putus asa serta melemahkan tanggung jawab. Menurut Tyrer (dalam Kusuma 2008), bahwa yang menentukan stres atau tidaknya individu adalah kemampuan menyesuaikan diri dengan perubahan-perubahan yang terjadi.

Gangguan pada sistem endokrin (hormonal) pada mereka yang mengalami stres adalah kadar gula yang meninggi, dan bila hal ini berkepanjangan bisa mengakibatkan yang bersangkutan menderita penyakit kencing manis (diabetes millitus), gangguan hormonal lain misalnya pada wanita adalah gangguan menstruasi yang tidak teratur dan rasa sakit (dysmenorrhoe) (Hawari, 2008).

Kecemasan adalah suatu keadaan tegang yang berhubungan dengan ketakutan, kekhawatiran, perasaan-perasaan bersalah, perasaan tidak aman dan kebutuhan akan kepastian. Kecemasan pada dasarnya 
merupakan sebuah respons terhadap apa yang terjadi atau antisipatif, namun faktor dinamik yang dapat mempercepat kecemasan tidak disadari (Semiun, 2006).

Peristiwa-peristiwa menyenangkan juga menimbulkan stres, meskipun kebanyakan stres berawal dengan peristiwa-peristiwa negatif, menyakitkan dan tidak diharapkan dalam kehidupan kita. Situasi yang sama dapat dilihat secara berbeda oleh dua individu. Yang satu dapat memandang situasi yang ada sebagai tantangan yang menarik sementara individu yang lain memandang situasi tersebut sebagai ancaman terhadap kehidupannya. Perbedaan cara pandang dan reaksi terhadap suatu peristiwa yang sama pada saat yang berbeda, tergantung pada keadaan perasaan dan fisik saat itu (Sriati, 2008)

Hal ini didukung oleh hasil penelitian Mahbubah (2006) dan) yang menyatakan bahwa ada hubungan antara stres dengan siklus menstruasi. Frustasi terjadi apabila gerak ke arah tujuan yang diinginkan terhambat atau tertunda. Berbagai hambatan, baik eksternal maupun internal, dapat mengganggu usaha seseorang untuk mencapai tujuan. Frustasi bisa menjadi sumber agresi yang diekspresikan secara langsung terhadap orang atau benda lainnya. Atau dengan kata lain agresi merupakan salah satu bentuk respon terhadap frustasi. Ketika dalam situasi frustasi, biasanya seseorang tampak gelisah dan tidak senang, mereka menggerutu, resah, dan lain sebagainya. Sebagian diantara mereka mengungkapkan perasaan marah, mereka menendang dan memukul, bahkan seringkali merusaknya.

Pada keadaan stres terjadi aktivasi pada amygdala pada sistem limbik. Sistem ini akan menstimulasi pelepasan hormone dari hipotalamus yaitu corticotropic releasing hormone (CRH). Hormon ini secara langsung akan menghambat sekresi GnRH hipotalamus dari tempat produksinya di nukleus arkuata. Proses ini kemungkinan terjadi melalui penambahan sekresi opioid endogen. Peningkatan CRH akan menstimulasi pelepasan endorfin dan adrenocorticotropic hormone (ACTH) ke dalam darah. Endorfin sendiri diketahui merupakan opiat endogen yang peranannya terbukti dapat mengurangi rasa nyeri. Peningkatan kadar ACTH akan menyebabkan peningkatan pada kadar kortisol darah.

\section{b. Stresor Sosial}

Menurut Sukmadinata (2007) menyatakan bahwa lingkungan institusi pendidikan adalah yang paling utama mempengaruhi pendidikan. Dimana individu khususnya mahasiswa memerlukan hubungan dengan lingkungan yang menggiatkannya, merangsang perkembangannya, atau memberikan sesuatu yang diperlukan. Oleh karena itu, pada umumnya individu manusia (mahasiswa) senantiasa menyesuaikan dirinya dengan lingkungan. Dengan demikian, hubungan antara individu yang berinteraksi senantiasa merupakan hubungan timbal balik yang saling berpengaruh terhadap lingkungan. Dengan menciptakan interaksi sosial mahasiswa yang baik di lingkungan institusi antara mahasiswa dengan pengajar, mahasiswa dengan mahasiswa lain ataupun dengan karyawan, akan membuat mahasiswa merasa senang, dan betah berada di lingkungan institusi. Sehingga kegiatan belajar di institusi dapat berjalan dengan baik karena adanya suatu motivasi atau dorongan yang positif dari lingkungan institusi yang menurunkan tingkat stress pada mahasiswi.

Responden dengan stresor sosial tidak baik yang siklus menstruasi tidak normal adalah sebanyak 12 orang $(57,1 \%)$, dan dan yang siklus menstruasi normal adalah sebanyak 9 orang (42,9\%). Sementara itu, responden dengan stresor sosial baik yang siklus menstruasi tidak normal adalah sebanyak 15 orang $(31,9 \%)$, dan yang siklus menstruasi normal adalah sebanyak 32 orang $(68,1 \%)$.

Membina hubungan dengan orang lain adalah keterampilan-keterampilan untuk berhubungan dengan orang lain yang merupakan kecakapan emosional yang mendukung keberhasilan dalam bergaul dengan orang lain. Keterampilan membina hubungan merupakan keterampilan yang menunjang popularitas, kepemimpin an dan keberhasilan. Individu yang hebat dalam keterampilan ini akan sukses dalam bidang apapun yang berhubungan dengan pergaulan interaksi dengan orang lain. Interaksi individu yang baik menciptkan 
kondisi yang mengguntungkan bagi mahasiswi.

\section{KESIMPULAN}

Berdasarkan hasil penelitian tentang pengaruh stressor psikologis dan stresor sosial terhadap siklus menstruasi mahasiswa kebidanan maka dapat disimpulkan sebagai berikut:

a. Terdapat pengaruh antara stressor psikologis terhadap siklus menstruasi

b. Terdapat pengaruh antara stressor sosial terhadap siklus menstruasi

\section{DAFTAR PUSTAKA}

Cakir $M$ et all.2007. Menstrual Patternand Common Menstrual Disorders Among University Student inTurkey. Pediatrik International. 49(6) : 938-42.

Guyton, C. A. \& Hall, J. E. 2006. Female Physiology Before Pregnancy and Female Hormones. In: Textbook of Medical Physiology. 11thed. 1011-1022.

Hawari,. 2008. Manajemen Stres Cemas Dan Depresi. Fakultas Kedokteran Universitas Indonesia: Jakarta.

Kusuma, Pergiwati, P., Gusniarti, U. 2008. Gifted review: Hubungan antara penyesuaian diri sosial dengan strespada siswa akselerasi.Universitas Indonesia: Jurnal Keberbakatan \& Kreativitas 2008, Vol. 02, No. 01, 31-43.

Mahbubah. 2006. Hubungan Stres dengan Siklus Menstruasi pada Wanita Usia 20-29 Tahun di kelurahan Sidoharjo, Kecamatan Pacitan, KabupatenPacitan.diakses tangga15 April 2015.

Rice, Philip L. 1992. Stress and Health (2nd ed.). California: Wadsworth,

Sandhi. 2014. Hubungan Tingkat Stres Dengan Siklus Menstruasi Pada Mahasiswa Diii Kebidanan Jalur Reguler Akademi Kebidanan Uniska Kendal. Jurnal Ilmu Kesehatan. Vol. 5 No. 2, Juli 2014

Semiun. 2006. Kesehatan Mental 2 . Yogyakarta: Kanisius
Sriati, A., 2008. Tinjauan tentang Stres. Makalah Fakultas Ilmu Keperawatan. UNPAD. Jatinangor. Di unduh pada tanggal 1 April 2016.

Sukmadinata. 2007. Landasan Psikologi Proses Pendidikan. Bandung: Remaja Rosdakarya

Sukhraini, Isra. 2010. Hubungan Stres Dengan Siklus Menstruasi Yang Tidak Teratur Pada Mahasiswi Fakultas Kedokteran USU Angkatan 2007. http://repository.usu.ac.id/. Diakses tanggal 7 April 2016.

Wiknjosastro, H. 2009. Ilmu Kebidanan. Edisi ke3. Jakarta: Yayasan Bina Pustaka Sarwono Prawirohardjo.

Wiramihardja S.A., 2007. Pengantar Psikologi Abnormal. Bandung.Refika Aditama.

Wulandari, Lita Hadiati. 2011. Gambaran Stres Di Bidang Akademik Pada Pelajar Sindrom Hurried Child Di Sekolah Chandra Kusuma. http://repository.usu.ac.id. Diakses pada tanggal 16 April 2016 